Article

\title{
The Influence of ISO 9001 \& ISO 14001 on Sustainable Supply Chain Management in the Textile Industry
}

\author{
Dominik Zimon $^{1, * \mathbb{C}}$, Peter Madzik ${ }^{2} \mathbb{C}$ and Robert Sroufe ${ }^{3}$ \\ 1 Department of Management Systems and Logistics, Rzeszow University of Technology, \\ 35-959 Rzeszow, Poland \\ 2 Department of Management, Catholic University in Ruzomberok, Nabrezie Jana Pavla II. c. 15, \\ 05801 Poprad, Slovakia; peter.madzik@ku.sk \\ 3 Department of Business Management, Duquesne University, Pittsburgh 15282, USA; sroufer@duq.edu \\ * Correspondence: zdomin@prz.edu.pl
}

Received: 30 March 2020; Accepted: 21 May 2020; Published: 23 May 2020

check for updates

\begin{abstract}
The examination of implementing ISO standards can provide new insight as to their quality and environmental management benefits. These insights can be more impactful in manufacturing sectors and especially textiles as this sector is known for its environmental degradation and questionable supply chain practices. This exploratory study investigates the extent to which organizations that implement either ISO 9001 or 14001 standards impact sustainable supply chain management (SSCM). We also investigate the extent to which these two standards improve SSCM for the textile industry within a block of European countries consisting of Poland, Slovakia, and the Czech Republic. In this empirical study, we use several measures to help identify the extent of impacts of examined standardized management systems on improvements in different processes of SSCM. Our contributions to the field include finding that quality management systems support environmental processes, relationships with stakeholders, processes within the supply chain, and SSCM. Other findings include implementing environmental management system standards impact the rationalization of other processes. Finally, we find more significant supply chain impacts with the implementation of both standards than by either standard alone. The study concludes with suggestions for extension of this study and opportunities for further research.
\end{abstract}

Keywords: SSCM; ISO 9001; ISO 14001; textile industry

\section{Introduction}

The textile industry contributes to environmental degradation and climate change. Raut et al. [1] recognize that the textile sector, therefore, significantly influences the socio-economic and environmental dimensions of sustainability. The textile industry not only consumes a significant amount of resources, pollutes the environment during the production and delivery, but also generates significant amounts of waste, of which only a small part is recycled [2-4]. Prior researchers have claimed that the textile industry is important to look for insights on how to improve sustainable supply chain management (SSCM) [5-8]. Therefore, we can see the continuous improvement of SSCM is a priority for enterprises operating in manufacturing industries, not only because of opportunities to improve an image, but also because of the growing environmental awareness of potential consumers. Jawaad and Zafar [9], and Kang et al., [10] with their work on customers and enterprises from the textile industry, claim that environmental concerns have led to awareness among customers when making purchasing decisions. The emphasis on ecological activities means that some customers are guided by care for the environment when making these decisions. Consumers are an essential stakeholder for many reasons, and an industry that can quickly respond to changing customer trends can gain a competitive 
advantage. Based on the literature, some of the most important trends shaping entire markets are digitization, globalization, and care for environmental protection [11].

According to Moorhouse and Moorhouse [12], all stakeholders in the textile sector should be involved in activities aligned with sustainable development. Today sustainability is not a passing fad or new idea but increasingly a business model [13]. Although this approach requires tremendous effort and resources, remaining on the sidelines of such activities may in the near future lead to significant damage to a firm's image, and weaken its market position [14]

It can be concluded that organizations operating in the textile industry specifically, and manufacturing in general, must look for solutions to improve the functioning of the supply chain in key aspects of their business, including quality [15], environment management, and innovation management [16-18]. Although companies in the textile industry have implemented many practices to improve SSCM, the literature on the subject lacks research on the impact of standardized management standards on SSCM in this industry. Why would this be important? Because, ISO standards can help this industry sector and other manufacturers as they enable a firm's ability to effectively design, produce, and deliver quality products and services with fewer impacts on the environment. The combination of quality management in ISO 9001 and environmental management in the ISO 14001 standards can meet changing customer needs by including more top-management involvement in, and measurement of manufacturing practices. Despite widespread international acceptance, the implementation of these standards and their benefits still provide opportunities for new insights as impacts across all industry sectors and countries are not uniform.

One way to improve SSCM can be to implement the requirements of standardized management systems. While there are several studies dealing with the impact of the ISO 14001 standard on sustainable business management [19-21] and some discussing its impact on SSCM [22,23], there is a lack of research into the implementation of the requirements of ISO 14001 in the textile industry [24]. From a review of the literature, we find an opportunity to assess the impact of implementing a standardized quality management system on SSCM in the textile industry. There is a gap in the literature that this study should help to fill as we attempt to answer several questions exploring the extent to which the implementation of the requirements of ISO 9001 and ISO 14001 support SSCM in a single yet dynamic industry.

\section{Review of the Literature}

The ISO 9001 is the de facto standard for quality management systems, enjoying considerable interest among all types of businesses globally [16]. When reviewing the literature on standardized quality management systems, it can be stated that while its impact on organization management is quite often and widely acknowledged, there are still opportunities for studies examining its impact on supply chain management and SSCM. It should be noted that the ISO 9001 standard is a customizable system and, due to its global use, it can support the implementation of the strategies of enterprises on operationally and tactically $[25,26]$. It can be assumed that the implementation of this standard's requirements can also help improve the integrated management of internal processes [27,28], as well as cooperation with suppliers and external stakeholders. It can support the implementation of the objectives adopted by organizations co-creating supply chains. This view is confirmed by prior studies such as those of Dellana and Kros [29], Zimon and Madzík, [30] and Bastas and Liyanage [31].

Issues regarding the impact of the ISO 14001 standard on the sustainable management of enterprises and supply chains has been raised in the literature. However, we have found that the literature lacks studies investigating the impact of the ISO 14001 standard on SSCM in the textile industry. This industry is dynamic, having a strong dispersion of individual links in the supply chain resulting from efforts to minimize labor and production costs, the widespread adoption of outsourcing of finished products far away from sales markets, problems with managing the return of post-seasonal clothing items, or the implementation of a fast fashion strategy based on a maximum shortening of product 
flow time in supply chains to name a few of its characteristics [3,32]. Here, we see research and the impact of ISO 14001 on SSCM in the textile industry as necessary and justified.

Our work in this field of inquiry and review of the literature has noted that organizations often implement the requirements of several standards and integrate them. Flynn and Flynn [33] and Casadesús and de Castro [34] emphasize the need to implement standardized management systems in the supply chain, suggesting that there are strong relationships between quality management and supply chain management. The proper use of these systems will strengthen the competitive position. The implementation and integration of several systems can strengthen positive effects [35]. The main task of integrating management systems is to streamline and optimize processes implemented within the enterprise and to ensure the cooperation of individual management systems while taking into account external processes implemented by suppliers and subcontractors. Foster [36] emphasizes that integrated management systems allow supply chains to function more effectively in an increasingly risky external environment. The essence of integration is the coherent management of many aspects of the supply chain, which means that it is necessary to simultaneously manage quality, environmental impacts, and perform other tasks of the supply chain [37]. In order to effectively create an integrated system in the supply chain, it is necessary to identify the activities and processes implemented in it through its individual links (i.e., suppliers, subcontractors, distributors, etc.). In addition to identifying processes affecting the organization of product flow and comprehensive customer service in the supply chain, management processes should be identified and reviewed, and when necessary, corrective actions implemented [26,38]. Identifying these processes and then including them in the integrated management system will allow their correct implementation and support compromises to implement the best solutions developed on the basis of a combination of sometimes contradictory goals formulated in individual systems [39]. We, therefore, posit that the integration of the ISO 9001 standard focused on improving internal processes and ISO 14001 based on the implementation of pro-environmental solutions can support SSCM. The more features that the ISO 14001 standard has in common with the ISO 9001 standard, the more these standards enable developing a strategy within which environmental issues are integrated into the daily activities of the organization $[40,41]$.

The Polish, Slovak, and Czech textile industry is characterized by compliance with European standards regulating the issues of quality and safety of materials, and social responsibility of producers [42]. This industry is dependent on natural resources such as the raw materials needed to create materials, resources used in production and human resources [43]. Enterprises operating in this industry in Eastern and Central Europe need solutions aimed at increasing innovation, increasing their share in foreign markets, as well as the optimization of supply chains and production processes $[3,44]$. Additionally, local consumers are increasingly aware of the origin of products, the production process, and the employment conditions of employees in this sector [45]. This awareness will affect the future of the clothing and textile sector, for which the challenges include [44]:

- $\quad$ sustainable production;

- pro-ecological approach to the production and implementation of logistics processes;

- hiring employees ensuring optimal working conditions;

- use of local suppliers and subcontractors at every stage of production and distribution.

Support for the proper integration of these challenges may be the implementation of the standardized quality management and environmental systems that support vital business processes and supply chains that manage and avoid risks $[29,30]$.

The research in this study explores the impact of implementing the requirements of ISO 9001 and ISO 14001 on key processes in supply chains. We assume that many of the elements of quality and environmental management are connected with SSCM. Therefore, the scope of this study is to examine elements of implemented found in logistics subsystems, i.e., supply, production, distribution, and reverse logistics, and to try and include consumers and external stakeholders. For the purposes of this study, we looked at three groups of benefits: internal, external, and supply chain management (SCM). 
These aspects allowed for a broad view of the functions of supply chains and a focus on the needs of individual links in the supply chain as well as external and internal stakeholders. This is important because, as pointed out by Freise [46] and Baskaran et al. [47], supply chains in the textile industry face a significant number of sustainability issues at every stage of their operations. Oelze [11] found that the correct implementation of SSCM in the textile industry requires a constant improvement of internal processes, formal cooperation, and a focus on the requirements of external stakeholders.

\section{Methodology}

The main goal of the research was to determine the extent to which standardized management systems, i.e., ISO 9001 and ISO 14001, influence the improvement of processes supporting SSCM in the textile industry, with a block of European countries. In order to better operationalize the research, we developed the following key research questions. We examine these questions through primary data collection and inferential statistics. The research questions are:

RQ1. To what extent do organizations that only implement a quality management system according to ISO 9001 determine its impact on improving selected aspects of SSCM?

RQ2. To what extent do organizations that only implement the ISO 14001 standard determine its impact on improving selected aspects of SSCM?

RQ3. Do ISO 9001 and ISO 14001 standards support each other in the context of improving SSCM in the textile industry?

The potential sample included 600 organizations operating in the three chosen countries. Fully completed forms were received from a resulting sample of 105 organizations (a 17\% response rate), with 66 engaged in the production of clothing and 39 in textile production organizations from the textile industry (operating in Poland, Slovakia, and the Czech Republic), that have implemented the ISO 9001, the ISO 14001 standard, or both systems. The implementation of the requirements of ISO 9001 or ISO 14001 and conducting business in the textile industry were the basic conditions classifying organizations for research in this study. The online survey was addressed to top managers (targeting managing directors). The participants could access their survey via an individual link sent per mail. The actual survey was preceded by a pretest phase of the survey instrument. The pretest involved 15 organizations helping to check it for clarity and understanding of individual items. The survey structure encompassed five primary groups of questions addressing the following central themes: organizational characterization, internal benefits (on a 5-point scale from 1-no impact, to 5-very strong impacts), external benefits (on a 5-point scale from 1-no impact, to 5-very strong impacts), SSCM (on a 5-point scale from 1-no impact, to 5-very strong impacts) and respondent data.

The organizations involved in this study were divided into three groups. The first group consists of organizations that decided to implement only the ISO 9001 standard (45 companies). The second consists of those that implemented the ISO 14001 standard (32 companies). The third group consists of organizations that decided to implement the requirements of both standards (28 companies). The empirical survey research process was completed in August and September of 2019. The characteristics of the sample are in Table 1.

Table 1. Characteristics of the organizations.

\begin{tabular}{ccc}
\hline Feature of the Test & Description Information from the Test Sample & \\
\hline \multirow{3}{*}{ Size of the organization } & Small & 53 \\
& Medium & 42 \\
& Large & 20 \\
\hline \multirow{3}{*}{ Management systems } & ISO 9001 & 45 \\
& ISO 14001 & 32 \\
Country & ISO 9001 \& ISO 14001 & 28 \\
& Poland & 57 \\
& Slovakia & 21 \\
& Czech Republic & 27 \\
\hline
\end{tabular}


The stratification variable employed was the type of organization. Organizations that have implemented the ISO 9001 system, the ISO 14001 system, or both at the same time were examined. The questions focused on three areas - internal benefits, external benefits, and SSCM benefits. These three areas were divided into nine questions. Internal benefits included three questions: improved environmental performance, consumption and cost reduction, design of products taking into account environmental aspects. External benefits topic consisted of three questions: better adaptation to the changing business landscape, the increase in environmental awareness, improving cooperation with external stakeholders. Supply chain management consisted of three questions covering: rationalization of reverse logistics, green shipping and distribution, and supply chain integration (technological and physical levels). These nine questions were measured on Likert 5-point scales. Along with these variables, the identification variables mentioned in Table 1 were used for statistical analysis. An overview of the main characteristics of these variables is shown in Table 2.

Table 2. Main characteristics of variables.

\begin{tabular}{|c|c|c|c|}
\hline Group & Question/Variable & Abbreviation & Answers \\
\hline \multirow[t]{3}{*}{ SSCM } & $\begin{array}{l}\text { Rationalization of } \\
\text { reverse Logistics }\end{array}$ & Rat_RL & \multirow{3}{*}{$\begin{array}{l}\text { Scale from } 1 \text { (no impact) } \\
\text { to } 5 \text { (very strong impacts) }\end{array}$} \\
\hline & $\begin{array}{l}\text { Green shipping and } \\
\text { distribution }\end{array}$ & Green_SD & \\
\hline & $\begin{array}{l}\text { Supply chain integration } \\
\text { (technological and } \\
\text { physical level) }\end{array}$ & SCh_Integ & \\
\hline \multirow[t]{3}{*}{ External benefits } & $\begin{array}{l}\text { Improved environmental } \\
\text { performance }\end{array}$ & Impr_EP & \multirow{3}{*}{$\begin{array}{l}\text { Scale from } 1 \text { (no impact) } \\
\text { to } 5 \text { (very strong impacts) }\end{array}$} \\
\hline & $\begin{array}{l}\text { Consumption and cost } \\
\text { reduction }\end{array}$ & Cons_CR & \\
\hline & $\begin{array}{l}\text { Design of products } \\
\text { taking into account } \\
\text { environmental aspects }\end{array}$ & Enviro_D & \\
\hline \multirow[t]{3}{*}{ External benefits } & $\begin{array}{l}\text { Better adaptation to the } \\
\text { changing business } \\
\text { landscape }\end{array}$ & Change_A & \multirow{3}{*}{$\begin{array}{l}\text { Scale from } 1 \text { (no impact) } \\
\text { to } 5 \text { (very strong impacts) }\end{array}$} \\
\hline & $\begin{array}{l}\text { The increase in } \\
\text { environmental } \\
\text { awareness }\end{array}$ & Enviro_A & \\
\hline & $\begin{array}{l}\text { Improving cooperation } \\
\text { with external } \\
\text { stakeholders }\end{array}$ & Stakeholders & \\
\hline
\end{tabular}

The data were tested on scale reliability. Cronbach's alpha was used as a measure of reliability. Two tests, namely the Kolmogorov-Smirnov and Shapiro-Wilk, were used to test the normality of data. The results were processed at two levels. Descriptive and graphical statistics tools were used in the first basic level. Position, variability, and asymmetry descriptive statistics were used to show the main characteristics of examined variables. We use several descriptive statistics such as mean, confidence intervals for mean, standard deviation, kurtosis, skewness etc. These measures help us to identify the extent of the impacts of examined standardized management systems on improvements in different processes of SSCM. In the second level of assessment, the correlation between variables was examined through bivariate correlation analysis and later through confirmatory factor analysis. Pearson linear correlation coefficient, as well as $p$-values (as significance levels), were used as main measures to express the intensity of relationships. We used principal component analysis with Varimax rotation as an extraction method. Bivariate correlation analysis helps to quantify the intensity of a 
relationship between all nine scale variables. Factor analysis helps to identify latent relationships in correlation structure and enables the extraction and explanation of new factors affecting improvements in different processes of SSCM. Hypothesis testing utilized by one-way analysis of variance (ANOVA) to test differences between organizations with ISO 9001, with ISO 14001, and with both systems.

\section{Analysis and Results}

The research assessed 105 valid survey responses with the sample, including 45 organizations that implemented the quality management system according to the ISO 9001 standard, 32 organizations implemented the requirements of the ISO 14001 standard, and 28 organizations complied with the requirements of the ISO 9001 and ISO 14001 standards. Figure 1 presents the general distribution of answers presented by individual groups. Respondents were rated on a five-point scale from one, no impact, to five, very strong impacts.

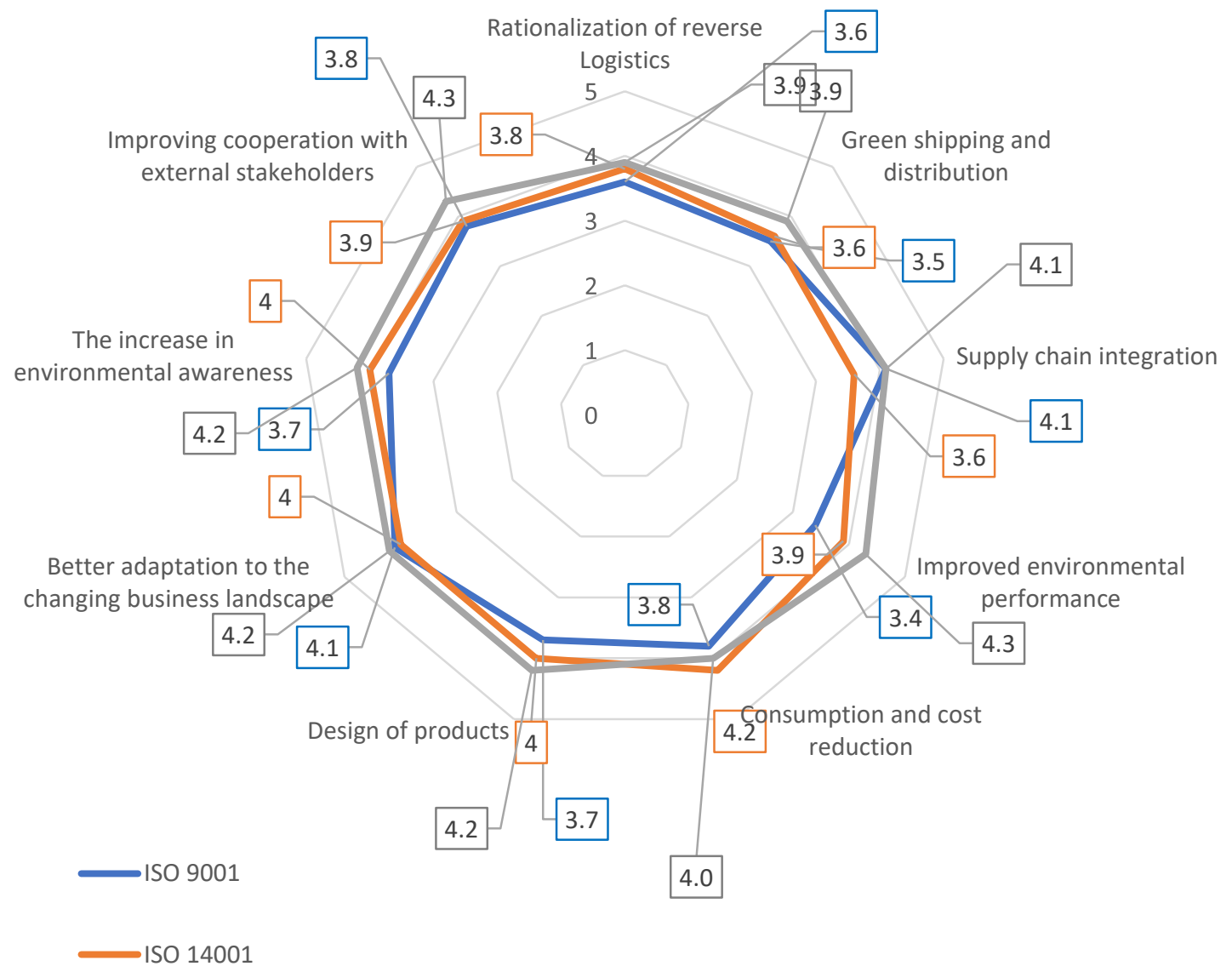

Figure 1. Assessment of examined aspects.

Analysis of the distribution of responses presented in Fig. 1 shows that:

- In the group of organizations that only implemented the requirements of the ISO 9001 standard, the average rating of all nine aspects examined was 3.7. On this basis, it can be concluded that a standardized quality management system has a noticeable impact on the improvement of the studied areas. According to respondents, the implementation of ISO 9001 requirements most streamlines the process of integration of individual links in the supply chain and facilitates adaptation to changing market conditions. The high assessment of these aspects may result from the fact that the ISO 9001 standard emphasizes the need to understand the context of the organization, i.e., a set of factors that affect the sense of the organization's existence and its ability to develop sustainably. The context of the organization includes internal factors, such as values, 
culture, knowledge, and effects of the organization, as well as external factors such as the legal, technological, competitive, market, cultural, social, and economic environment. The ISO 9001 standard highlights the importance of managing relationships with external stakeholders and suppliers. Effective implementation of the above requirements may have a positive impact on the efficiency of processes implemented by enterprises [48].

- Considering initially the assessments of the respondents who have implemented only the requirements of the ISO 14001 standard, it can be seen that the average rating of all areas is relatively high as it is 3.9 on a five-point scale. According to respondents, the ISO 14001 standard most strongly supports such aspects as consumption and cost reduction, design of products, better adaptation to the changing business landscape and the increase in environmental awareness.

- The choice of these aspects may be influenced by the fact that the ISO 14001 standard focuses on the effective use of resources and the image of a company for which sustainable development and respect for the natural environment is a priority in business [49]. In the ISO 14001 standard, it is also important to identify all entities cooperating with the organization and to analyze their needs and expectations, which the organization should treat as applicable requirements. In the provisions of the standard, there was also a need to consider the perspective of the entire life cycle of products and services and to consider which stages of their life cycle can be controlled or subject to the influence of the organization.

- In the group of organizations that decided to implement both standards, the average rating was the highest and amounted to 4.1. According to respondents, the implementation of two standardized management systems has a significant impact on virtually each of the aspects examined. The highest impact was recorded on improving cooperation with external stakeholders and improved environmental performance. The high assessment of these aspects may be influenced by the fact that the analyzed systems put great emphasis on the context of the organization's operation understood as the concept of strategic environmental management, i.e., the adaptation not only of the environmental policy, but the entire management system of the organization to the company's environment and circumstances affecting its functioning. It should also be emphasized that the ISO 9001 and ISO 14001 standards are compatible with each other, and their implementation may provide synergistic effects [50].

\subsection{Basic Statistics}

Of the 105 responding organizations, 45 had ISO 9001, 32 had ISO 14001, and 28 had both. Scale testing was performed using tau-equivalent reliability expressed through Cronbach's alpha. The total value of Cronbach's alpha was 0.729 , which makes the scale reliable. Table 3 shows the results of reliability testing in cases where variables were deleted. The results showed that all variables are relevant, and none of them cause a decrease in reliability.

Table 3. Reliability test results.

\begin{tabular}{ccccc}
\hline Variable & $\begin{array}{c}\text { Scale Mean If } \\
\text { Variable Deleted }\end{array}$ & $\begin{array}{c}\text { Scale Variance If } \\
\text { Variable Deleted }\end{array}$ & $\begin{array}{c}\text { Corrected Variable-Total } \\
\text { Correlation }\end{array}$ & $\begin{array}{c}\text { Cronbach's Alpha If } \\
\text { Variable Deleted }\end{array}$ \\
\hline Rat_RL & 31.219 & 14.557 & 0.452 & 0.697 \\
Green_SD & 31.333 & 15.628 & 0.347 & 0.715 \\
SCh_Integ & 30.990 & 15.606 & 0.266 & 0.730 \\
Impr_EP & 31.162 & 13.964 & 0.486 & 0.690 \\
Cons_CR & 30.962 & 15.345 & 0.324 & 0.719 \\
Enviro_D & 31.019 & 14.884 & 0.422 & 0.703 \\
Change_A & 30.867 & 14.501 & 0.451 & 0.697 \\
Enviro_A & 31.019 & 15.192 & 0.329 & 0.719 \\
Stakeholders & 30.971 & 13.759 & 0.562 & 0.676 \\
\hline
\end{tabular}

The five-point scale used was therefore confirmed to be reliable. Normality tests such as Kolmogorov-Smirnov as well as Shapiro-Wilk did not confirm the normal distribution of data for 
any of the nine variables studied. Data were left-slanted, and the median was at level four for each variable. Figure 2 shows the results of testing for normality.
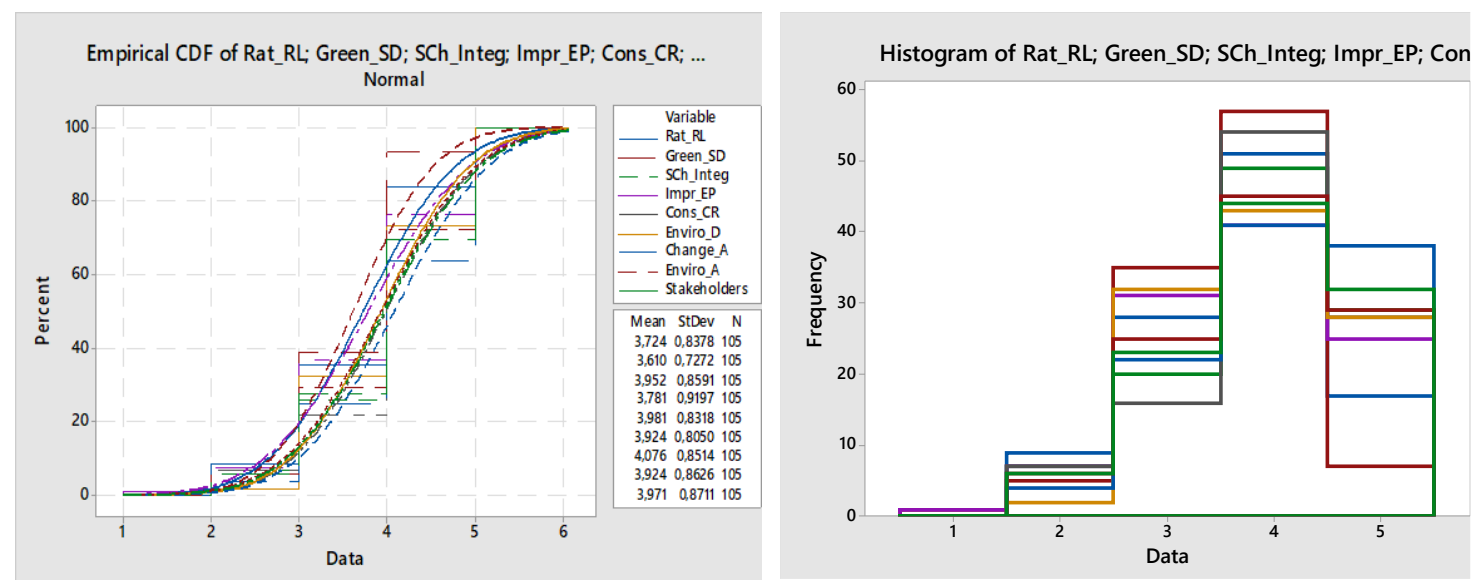

Figure 2. Normality examination; Empirical CDF (left) and histograms (right).

The highest values were achieved by the Change_A variable (4.076) and the lowest by the Green_SD variable (3.610). The high rating given by respondents to such a factor as "better adaptation to the changing business landscape" may be dictated by the fact that the examined systems require organizations to determine internal and external factors that are relevant to the objective of the strategic direction of the organization and affect its ability to achieve the intended results. Organizations, therefore, carry out research covering such areas, including competition activities, technology development, ethical values, or organizational culture. The information obtained helps companies better understand and adapt to changes in the environment. The respondents gave the lowest rating to such aspects as "green shipping and distribution", which may suggest that standardized management systems put emphasis on the correct implementation of processes affecting the quality and safety of implemented products, but the distribution processes themselves are not excessively exposed in the tested standards. Attention is focused mainly on the proper protection of products, which in practice is quite often carried out by external companies. Descriptive statistics of the examined variables are shown in Table 4.

Table 4. Descriptive statistics of examined variables.

\begin{tabular}{cccccccccc}
\hline Variable & Mean & $\begin{array}{c}\mathbf{9 5 \%} \\
\text { CIFMLB* }\end{array}$ & $\begin{array}{c}\mathbf{9 5 \%} \\
\text { CIFMUB* }\end{array}$ & $\begin{array}{c}\mathbf{5 \%} \\
\text { Trimmed } \\
\text { Mean }\end{array}$ & $\mathbf{N}$ & $\begin{array}{c}\text { Standard } \\
\text { Deviation }\end{array}$ & Median & Kurtosis & Skewness \\
\hline Rat_RL & 3.724 & 3.562 & 3.886 & 3.749 & 105 & 0.838 & 4.000 & -0.347 & -0.339 \\
Green_SD & 3.610 & 3.467 & 3.750 & 3.632 & 105 & 0.727 & 4.000 & 1.001 & -0.620 \\
SCh_Integ & 3.952 & 3.786 & 4.119 & 4.003 & 105 & 0.859 & 4.000 & -0.226 & -0.557 \\
Impr_EP & 3.781 & 3.603 & 3.959 & 3.823 & 105 & 0.920 & 4.000 & -0.282 & -0.379 \\
Cons_CR & 3.981 & 3.820 & 4.142 & 4.034 & 105 & 0.832 & 4.000 & 0.163 & -0.679 \\
Enviro_D & 3.924 & 3.768 & 4.080 & 3.937 & 105 & 0.805 & 4.000 & -0.947 & -0.086 \\
Change_A & 4.076 & 3.911 & 4.241 & 4.127 & 105 & 0.851 & 4.000 & -0.539 & -0.529 \\
Enviro_A & 3.924 & 3.757 & 4.091 & 3.971 & 105 & 0.863 & 4.000 & -0.526 & -0.401 \\
Stakeholders & 3.971 & 3.803 & 4.140 & 4.024 & 105 & 0.871 & 4.000 & -0.489 & -0.478 \\
\hline
\end{tabular}

These overall results are stratified by type of organization. In the survey, three types of an organization's management systems (MS) were involved: those with an ISO 9001-based system, those with an ISO 14001-based system, and those that have both systems applied. We examined these systems to see if there is a statistical difference between groups using a one-way analysis of variance (ANOVA). The results of this analysis are shown in Table 5. 
Table 5. Results of ANOVA.

\begin{tabular}{|c|c|c|c|c|c|c|}
\hline & & Sum of Squares & $\mathrm{df}$ & Mean Square & F & Sig. \\
\hline \multirow{3}{*}{ Rat_RL ${ }^{*}$ MS } & Between Groups (Combined) & 2.553 & 2 & 1.277 & 1.849 & 0.163 \\
\hline & Within Groups & 70.437 & 102 & 0.691 & & \\
\hline & Total & 72.990 & 104 & & & \\
\hline \multirow{3}{*}{ Green_SD * MS } & Between Groups (Combined) & 2.442 & 2 & 1.221 & 2.371 & 0.099 \\
\hline & Within Groups & 52.548 & 102 & 0.515 & & \\
\hline & Total & 54.990 & 104 & & & \\
\hline \multirow{3}{*}{ SCh_Integ * MS } & Between Groups (Combined) & 5.920 & 2 & 2.960 & 4.262 & 0.017 * \\
\hline & Within Groups & 70.842 & 102 & 0.695 & & \\
\hline & Total & 76.762 & 104 & & & \\
\hline \multirow{3}{*}{ Impr_EP * MS } & Between Groups (Combined) & 13.193 & 2 & 6.597 & 8.999 & $0.000^{* *}$ \\
\hline & Within Groups & 74.769 & 102 & 0.733 & & \\
\hline & Total & 87.962 & 104 & & & \\
\hline \multirow{3}{*}{ Cons_CR $*$ MS } & Between Groups (Combined) & 2.509 & 2 & 1.255 & 1.842 & 0.164 \\
\hline & Within Groups & 69.453 & 102 & 0.681 & & \\
\hline & Total & 71.962 & 104 & & & \\
\hline \multirow{3}{*}{ Enviro_D* MS } & Between Groups (Combined) & 4.039 & 2 & 2.019 & 3.251 & $0.043 *$ \\
\hline & Within Groups & 63.352 & 102 & 0.621 & & \\
\hline & Total & 67.390 & 104 & & & \\
\hline \multirow{3}{*}{ Change_A ${ }^{*}$ MS } & Between Groups (Combined) & 0.907 & 2 & 0.454 & 0.621 & 0.539 \\
\hline & Within Groups & 74.483 & 102 & 0.730 & & \\
\hline & Total & 75.390 & 104 & & & \\
\hline \multirow{3}{*}{ Enviro_A ${ }^{*}$ MS } & Between Groups (Combined) & 4.463 & 2 & 2.231 & 3.121 & $0.048 *$ \\
\hline & Within Groups & 72.927 & 102 & 0.715 & & \\
\hline & Total & 77.390 & 104 & & & \\
\hline \multirow{3}{*}{ Stakeholders ${ }^{*}$ MS } & Between Groups (Combined) & 3.789 & 2 & 1.894 & 2.572 & 0.081 \\
\hline & Within Groups & 75.125 & 102 & 0.737 & & \\
\hline & Total & 78.914 & 104 & & & \\
\hline
\end{tabular}

* $p$-value less than $0.05 ;{ }^{* *} p$-value less than 0.01

Type of implemented management system was statistically significant in four variables: SCh_Integ $(p$-value $=0.017)$, Impr_EP $(p$-value $=0.000)$, Enviro_D $(p$-value $=0.043)$, and Enviro_A $(p$-value $=0.048)$. This can be interpreted in the following manner:

- Organizations that have only implemented the requirements of the ISO 14001 standard significantly lower its positive impact on supply chain integration than organizations that have also decided to implement the requirements of the ISO 9001 standard. It is therefore believed that the ISO 9001 standard emphasizing the importance of beneficial relationships with suppliers while including the needs and expectations in the implementation strategy will a positive impact on integration processes in the supply chain.

- According to respondents, the requirements of the ISO 9001 standard have better Improved environmental performance than the ISO 14001 standard. It is influenced by the fact that the ISO 9001 standard is a quality management system that can support ecological processes, but this is not its main goal. This is also evident in aspects such as the design of products taking into account environmental performance and the increase in environmental awareness, in which the ISO 9001 standard has a lower impact than other systems. This does not change the fact that the ISO 9001 standard can improve processes related to sustainable development. In turn, ISO 14001 based on the concept that better environmental performance can be achieved when environmental aspects are systematically identified and managed to give a major contribution to sustainability through pollution prevention, improved environmental performance, and complying with applicable laws [51].

\subsection{Relationships between Variables}

Each of the nine variables has an ordinal scale, and therefore the relationships can be examined through a bivariate correlation analysis. This is a standard procedure for assessing the occurrence of 
the same or similar values in a pair of variables. The result is the correlation matrix found in Table 6 . The calculation of correlation coefficient values used the following formula.

$$
r=\frac{\sum_{i}\left(X_{i}-\bar{X}\right)\left(Y_{i}-\bar{Y}\right) /(N-1)}{\sqrt{\left(\sum_{i}\left(X_{i}-\bar{X}\right)^{2} /(N-1)\right) *\left(\sum_{i}\left(Y_{i}-\bar{Y}\right)^{2} /(N-1)\right)}}
$$

Table 6. Results of bivariate correlation analysis.

\begin{tabular}{|c|c|c|c|c|c|c|c|c|}
\hline & Rat_RL & Green_SD & SCh_Integ & Impr_EP & Cons_CR & Enviro_D & Change_A & Enviro_A \\
\hline \multirow[t]{2}{*}{ Green_SD } & 0.169 & & & & & & & \\
\hline & 0.086 & & & & & & & \\
\hline \multirow[t]{2}{*}{ SCh_Integ } & 0.142 & 0.155 & & & & & & \\
\hline & 0.149 & 0.115 & & & & & & \\
\hline \multirow[t]{2}{*}{ Impr_EP } & 0.270 & 0.302 & 0.218 & & & & & \\
\hline & $0.005^{* *}$ & 0.002 ** & $0.026^{*}$ & & & & & \\
\hline \multirow[t]{2}{*}{ Cons_CR } & 0.351 & 0.210 & -0.082 & 0.221 & & & & \\
\hline & 0.000 ** & $0.031^{*}$ & 0.406 & 0.024 * & & & & \\
\hline \multirow[t]{2}{*}{ Enviro_D } & 0.211 & 0.097 & 0.175 & 0.328 & 0.285 & & & \\
\hline & 0.031 * & 0.327 & 0.073 & 0.001 ** & $0.003^{* *}$ & & & \\
\hline \multirow[t]{2}{*}{ Change_A } & 0.353 & 0.219 & 0.268 & 0.132 & 0.151 & 0.289 & & \\
\hline & 0.000 ** & $0.025^{*}$ & $0.006^{* *}$ & 0.179 & 0.123 & $0.003 * *$ & & \\
\hline \multirow[t]{2}{*}{ Enviro_A } & 0.170 & 0.136 & 0.125 & 0.391 & 0.119 & 0.172 & 0.191 & \\
\hline & 0.083 & 0.166 & 0.205 & $0.000 * *$ & 0.228 & 0.080 & 0.051 & \\
\hline \multirow[t]{2}{*}{ Stakeh. } & 0.371 & 0.301 & 0.242 & 0.328 & 0.265 & 0.340 & 0.444 & 0.202 \\
\hline & 0.000 ** & 0.002 ** & 0.013 * & $0.001 * *$ & $0.006^{* *}$ & $0.000 * *$ & $0.000 * *$ & 0.039 * \\
\hline
\end{tabular}

${ }^{*} p$-value less than $0.05 ;{ }^{* *} p$-value less than 0.01 .

Correlation analysis revealed several statistically significant relationships. However, if we look at the correlation coefficients, we find that they are relatively low. The most intense relationship was between Stakeholders/Change_A $(r=0.444)$. In the literature, such values are considered to be a moderate correlation. Investigating the relationships between the variables thus did not show a significant dependency worthy of consideration. However, it is possible that there are latent indirect links between the variables that can explain their variability. Factor analysis was used to verify this assumption.

\subsection{Latent Relationships Analysis}

Our research was based on three areas: Internal benefits, External benefits, and SSCM. These areas were elaborated on a total of nine questions (variables). The latent links between these variables were verified through confirmatory factor analysis. The principal component analysis was used as an extraction method. Varimax with Kaiser normalization was used as a rotation method.

For this assessment, 105 organizations were processed with the resulting factors obtained on the basis of rotation converged in five iterations. The Kaiser-Meyer-Olkin measure of sampling adequacy was 0.743 , confirming the suitability of the data for dimension reduction. The values of commonalities did not drop below 0.20 , so there was no need to reduce the original number of nine variables that entered the factor analysis procedure. The choice of the number of factors followed the Kaiser rule, which determines the size of the eigenvalue of at least 1.0. Based on this rule, it was possible to extract three factors that explain $56.5 \%$ of the variability of all nine variables. However, these three factors differ slightly from the three groups we defined (external benefits, internal benefits, and SSCM). Their names, together with the results of the factor analysis, are shown in Table 7 , and values of correlation coefficients lower than 0.200 were not shown for overview purposes. 
Table 7. Results of factor analysis.

\begin{tabular}{|c|c|c|c|c|}
\hline \multirow[b]{2}{*}{ Variable } & \multirow[b]{2}{*}{$\begin{array}{l}\text { Communalities } \\
\text { Extraction }\end{array}$} & \multicolumn{3}{|c|}{ Loaded Factor Matrix } \\
\hline & & $\begin{array}{l}\text { F1: Challenges } \\
\text { from External } \\
\text { Stakeholders }\end{array}$ & $\begin{array}{l}\text { F2: Environmental } \\
\text { Responsibility }\end{array}$ & $\begin{array}{c}\text { F3: Process } \\
\text { Rationalization }\end{array}$ \\
\hline $\begin{array}{l}\text { Better adaptation to the } \\
\text { changing business } \\
\text { landscape }\end{array}$ & 0.645 & 0.736 & & 0.321 \\
\hline $\begin{array}{l}\text { Improving cooperation } \\
\text { with external } \\
\text { stakeholders }\end{array}$ & 0.582 & 0.717 & 0.228 & \\
\hline $\begin{array}{l}\text { Rationalization of } \\
\text { reverse Logistics }\end{array}$ & 0.511 & 0.687 & & \\
\hline $\begin{array}{l}\text { Design of products } \\
\text { taking into account } \\
\text { environmental aspect }\end{array}$ & 0.346 & 0.505 & 0.298 & \\
\hline $\begin{array}{l}\text { Improved environmental } \\
\text { performance }\end{array}$ & 0.709 & 0.211 & 0.815 & \\
\hline $\begin{array}{l}\text { The increase in } \\
\text { environmental } \\
\text { awareness }\end{array}$ & 0.608 & & 0.777 & \\
\hline $\begin{array}{l}\text { Green shipping and } \\
\text { distribution }\end{array}$ & 0.258 & 0.333 & 0.382 & \\
\hline $\begin{array}{l}\text { Supply chain integration } \\
\text { (technologiccal and } \\
\text { physical level) }\end{array}$ & 0.695 & 0.290 & & 0.756 \\
\hline $\begin{array}{l}\text { Consumption and cost } \\
\text { reduction }\end{array}$ & 0.732 & 0.524 & & -0.650 \\
\hline
\end{tabular}

Three factors were extracted. The first is F1, which consists mainly of variables: better adaptation to changing business landscape (Change_A; $r=0.736$ ), improving cooperation with external stakeholders (Stakeholders; $r=0.717$ ), rationalization of reverse logistics (Rat_RL; $r=0.687$ ), and design of products taking into account environmental aspect (Enviro_D; $r=0.505)$. Since these variables are related in some way to external stakeholders, this first factor was named as "F1: challenges from external stakeholders". The second extracted factor consisted mainly of three variables: improved environmental performance (Impr_EP; $r=0.815$ ), increase in environmental awareness (Enviro_A; $r=0.777$ ), and green shipping and distribution (Green_SD; $r=0.382$ ). These three variables are associated with environmental responsibility, so the second factor was named "F2: Environmental responsibility". The third factor consisted mainly of two variables: supply chain integration-technological and physical level (SCh_Integ; $r=0.756$ ), and consumption and cost reduction (Cons_CR; $r=-0.650$ ). Given the nature of these variables, the third factor was named "F3: Process rationalization".

These three factors have been the subject of prior research studies. The first factor was partly addressed by Matos and Hall [52] and by Matos and Silvestre [53], which point to the possibilities of managing value in the supply chain. Responsibility issues are often the subject of research that directly or indirectly focuses on the second factor identified by us, namely environmental responsibility. Carter and Easton [54] but also Govindan et al. [55] point out the perspective of corporate social responsibility and the triple bottom line. The third factor, namely process rationalization, is, in turn, focused on the supply chain in terms of both content [56] and information technology [57].

\subsection{Differences Between Organizations with ISO 9001, ISO 14001 and Both Systems}

In factor analysis, factor Z-score was recorded by linear regression. The three identified factors were further analyzed in terms of their intensity in individual types of organizations. Our research included organizations that had implemented the ISO 9001 system, organizations with the ISO 14001 system, and organizations with both systems. One-way ANOVA was used to test the differences 
between these organizations. This allows judgment of whether the meanings differ statistically between groups. The scale variable considered was the Z-score, calculated according to the following formula.

$$
z_{i}=\frac{x_{i}-\bar{x}}{s}
$$

The analysis showed that the first-factor "Challenges from external stakeholders" do not have a statistically significant difference between groups of organizations. However, a statistically significant difference emerged for the second and third factors - environmental responsibility and process rationalization. The graphical results of the Z-score are shown in Figure 3 (a detailed distribution of responses is presented in Figure 4), with the mean for all types of enterprises at level 0. Thus, if mean in any of the categories was higher than 0 , this meant that the factor was more significant for that type of organization. A value of less than 0 denotes less significance of the factor.

From this analysis, we can state that:

- Considering issues of environmental responsibility (F2), the implementation of the ISO 14001 standard and two standards (ISO 14001 and ISO 9001) can be recommended.

- The ISO 9001 standard itself has a slight impact on improving (decreasing) environmental liability (F2).

- Looking at the issue of process rationalization (F3), it can be stated that both the ISO 9001 standard and the implementation of two tested standards simultaneously have a significant impact on and serve to improve of this.

- Implementation of the requirements for only ISO 14001 has little impact on process rationalization $(\mathrm{F} 3)$.

Next, we discuss these results in more detail.

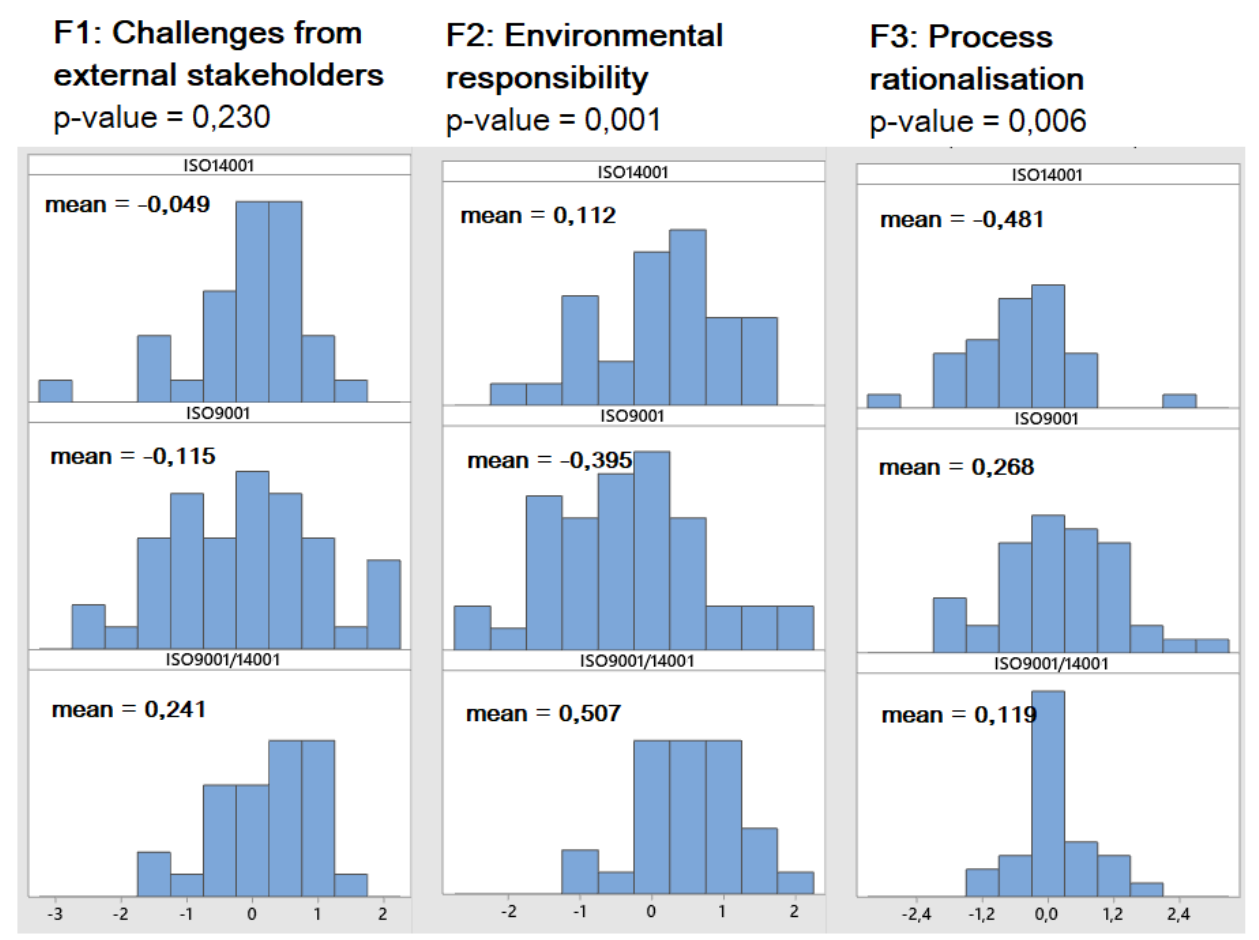

Figure 3. The graphical results of the Z-score. 


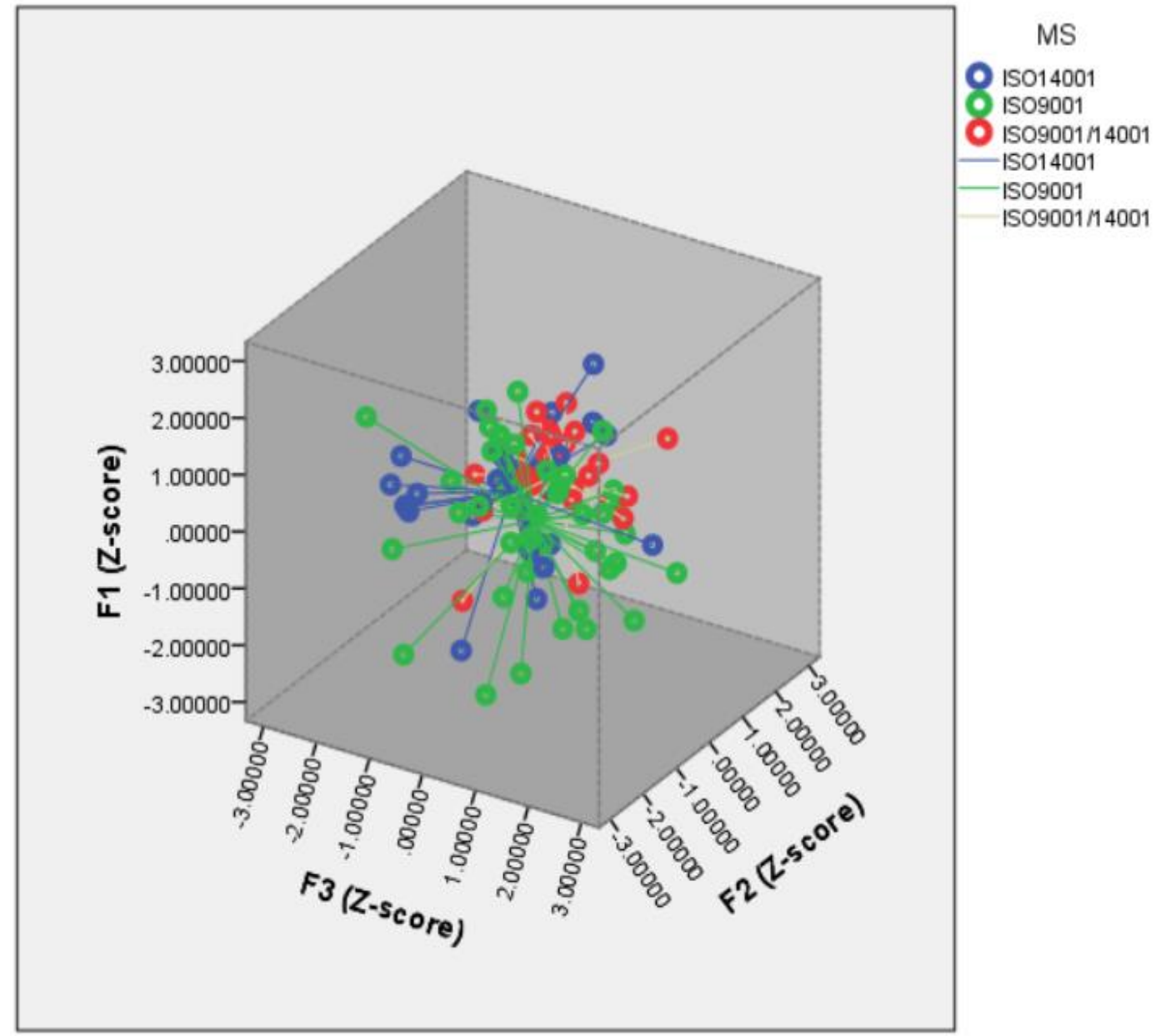

Figure 4. Detailed distribution of responses.

\section{Discussion}

Research on the ISO 9001 standard has been conducted for many years and on different organizational levels [20,58]. When reviewing the literature, we concluded that there is a gap regarding studies analyzing the impact of this standard (especially its new edition from 2015) on the functioning of processes related to SSCM. The need for research in this area is indicated by, among others Mijatovic et al. [59], Santos et al. [60], and Binner [61].

Based on the research and analysis carried out in this study, we conclude that the implementation of the requirements of ISO 9001: 2015 supports the integration of environmental processes. Moreover, the main advantages of this standard are focused on improving the relationship between cooperating links in the supply chain, internal improvement processes, and improving relationships with external stakeholders. Bastas and Liyanage [31] and Zimon et al. [62] also find that the implementation of ISO 9001 requirements can improve not only the underlying processes in the supply chain, but also contribute to the improvement of SSCM to some extent.

The ISO 9001 standard is a universal standard applicable to many types of organizations, and it is possible to develop a quality management system based on it that also supports various types of organizational goals. Therefore, if organizations co-creating supply chains strongly emphasize issues related to sustainability, and especially environmental management, then the requirements of ISO 9001 will support their correct implementation. They can be particularly useful in the area of minimizing errors, ensuring repeatability, reducing risk, or strengthening relationships in supply chains. Dellana et al. [38] suggest that ISO 9001 certification provides managers with a framework for structured risk management processes and collaboration with supply chain partners. This is due to the 
fact that the ISO 9001: 2015 standard, apart from emphasizing the improvement of key processes in the organization, has introduced risk management requirements [63,64].

Managers must be able to identify risks and take appropriate actions in proportion to the potential effect, making risk planning and execution much more proactive and integrative [36]. The global use of the ISO 9001 standard makes it relatively easy to integrate this system with the ISO 14001 standard. Many authors claim that both standards complement each other and can generate synergistic effects $[52,65]$. The results of this study build upon these prior studies while producing industry-specific insights from a block of European manufacturers.

We observed that the organizations implementing both systems rated their impact on the improvement of almost all aspects examined by us higher than those who implemented only one standard. The results show that the implementation of only the ISO 9001 standard has less impact on improving issues regarding environmental responsibility, while ISO 14001 only slightly impacts the rationalization of processes.

It is the implementation of both systems that already has a significant impact. It can be concluded that the ISO 9001 standard can be an effective SSCM support system. It is quite common practice for organizations to implement the ISO 9001 standard as a foundation for system management and then to supplement it with the requirements of the ISO 14001 standard [19,35], which allows the development of a system that streamlines the effective implementation of basic business processes and focuses it on the correct implementation of environmental issues [41,66,67]. A closer look at the results obtained by the organizations that have implemented only the ISO 14,001 standard offers the conclusion that this standard quite effectively supports the implementation of typically environmental processes. However, it is not as effective if we extend improvements of internal processes to external practices related to SSCM. Therefore, organizations operating in the industry that want to improve SSCM more comprehensively should decide to implement and integrate the requirements of both ISO 9001 and ISO 14001.

The main goals of the ISO 9001 and ISO 14001 standards were to develop uniformity in governance that would make businesses and decision makers aware of the fact that management of the company should be directed at the needs of diverse stakeholders, including but not limited to clients [68]. The main objectives of the ISO standards include:

(1) To show external customers, based on objective evidence that the company does everything within its capabilities to maximize their satisfaction.

(2) The introduction in the company of such a management system that allows entering a path to sustainable development, enabling appropriate targeting, minimization of losses, and improvement of the functioning of internal processes.

(3) To enable the company to creatively adapt the general requirements of the standard to the specifics of the business, size, sector, objectives, and strategies or existing market rules.

The ISO, with its requirements, gives any company guidance on the development of a quality management system architecture. This is based on a process level approach to development along with goals and metrics for continuous improvement [69]. The ISO 9001 and ISO 14001 standards guidelines helps with oversight of such areas in a company including but not limited to: the development of system documentation, management responsibility, employees' rights, methods of communication, maintenance management, acquisition and management, comprehensive implementation of the product or measurement, analysis, and improvement, etc.

It should be noted that the implementation of a standardized management system is an investment [70]. Practitioners and numerous empirical studies show that the implementation of standardized management systems is not an easy task, as it requires the people involved in the process extensive knowledge covering specifics of a company and the specific requirements of the system [71]. It should be noted that if done incorrectly or without an integrated approach, systems can be a source of additional problems and costs [72]. A properly developed and executed implementation process and 
the improvement of the quality and environmental management system according to ISO standards can lead to a number of internal and external benefits [73]. An analysis of the literature shows that the potential benefits are diverse and should be considered in the context of the expectations and objectives adopted in the implementation phase of the system. Based on the research results obtained in this study, it can be concluded that the implementation of each of the two standards studied can support SSCM in the manufacturing sector and textile industry. Greater effects will be obtained by supply chains in which participants decide to implement the requirements of both standards. However, the implementation of only one of these standards will still have positive effects. The proper functioning of standardized management systems requires time and is expensive. System maintenance generates costs that are not always acceptable to smaller organizations. The decision to implement the system should be well considered and consulted with partners who create supply chains [74]. Bearing in mind the problems faced by manufacturers in general and textile companies specifically, there are significant ecological issues to address. The implementation and integration of standardized systems will allow goals to be shared more systematically and consider the requirements of both internal and external stakeholders.

\section{Implications, Further Research Directions, and Limitations}

The results of this study contribute to theory development by exploring dimensions of quality and environmental management, positing new research questions in an exploratory look at multiple countries within a textile industry context, and confirming relationships posited in previous research. We suggest that continued research in this field should take into consideration the SSCM impacts of a manufacturer when assessing the impacts of ISO standards or when modeling supplier practices that include both ISO quality and environmental management systems. It would be interesting to examine the impact of the implementation of standardized management systems on SSCM from the perspective of links that play different roles in supply chains. In the future, we plan to examine the opinions of companies operating in Western and Eastern Europe and compare the results.

In this study, we show that both ISO 9001 and 14001 have the potential, when used under the right circumstances, to improve internal firm and external benefits across the supply chain. These systems can be a tool for both quality and environmental management that together have more dynamic benefits to those firms who implement them and their supply chains. These two standards assessed in this study can be applied across firms to leverage the synergies associated with implementation, such as environmental performance, reduced consumption and costs, improved product design, and the ability to adapt to a changing business landscape. Through the use of survey data and our analysis, the information from the respondents in this study builds on prior research further develops theory. It does this by providing a better understanding of ISO standard uncertainties, risks, benefits, and implications for awareness and cooperation with stakeholders within a supply chain. We find that ISO implementation does not make for a level playing field and that the level of integration and impact on supply chains will vary. This variance can allow some firms to obtain competitive advantages from implementation, while other plants will struggle with quality management and environmental management systems development, integration, and value propositions.

Limitations of this study include generalizability, causality, and empirical testing. The sample size, countries and the industry involved also limit the generalizability of the findings. The approach does not support causality or the ability to empirically test a broad set of propositions surrounding two ISO standards and objective measures of the benefits and supply chains. Suggestions for future research focus on the evolutionary rather than the revolutionary nature of ISO standard implementation within firms and their supply chains. To this end, there is a need for a qualitative and further quantitative assessment of relationships identified from this study. Researchers should expand supply chain constructs to include a supplier's operational, tactical, and strategic orientation. Additional research should test relationships between the orientation toward standards, competence, and performance. The proposed research can go beyond two standards and include combinations of other ISO standards 
such as 2600 for corporate social responsibility or 50,000 for energy management systems. It could even include more specific standards within the 14,000 series for product labeling. The development of more research on combinations of standards will help aid the assessment and understanding of impacts necessary to further advance sustainable supply chain management SSCM integration.

Focusing on the textile industry has broadened our empirical research from primary data sources. Secondary data sources, such as Compustat, with the help of event study analysis, were used since the utilization of standards within specific industries will be beneficial to advance research. This would be an extension of Graafland [23], along with Zimon and Madzík [24] or Bastas and Liyanage [75]. Further examination of other foundational studies and new data collection efforts will support and advance our understanding of standards, implementation, benefits, and how the attributes of standards extend to supply chains.

\section{Conclusions}

Our work in this study attempts to answer the question "To what extent do standardized quality and environment management systems support SSCM in a manufacturing industry?" The research analyzed the opinions of organizations that implemented a quality management system according to ISO 9001, ISO 14001, and both standards. Nine selected aspects of the firms studied were analyzed and classified into three groups: internal benefits, external benefits, and SSCM. Based on the obtained research results, it was found that each of the analyzed systems supports the correct implementation of the analyzed aspects, yet the impact strength is different. The ISO 9001 standard focuses mainly on improving internal processes in the examined organizations and cooperation between the links that form supply chains. This standard also has some impact on improving environmental processes. The implementation of the ISO 14,001 standard has quite a significant impact on the implementation of environmental processes in the examined organizations. Organizations that have implemented both standards have the most favorable results. We concluded that these standards complement and contradict each other in achieving their objectives.

The examined aspects of the firms in this study were classified into three successive groups: challenges from external stakeholders, environmental responsibility, and process rationalization. The analyses also showed that the implementation of both standards has the most significant impact on the improvement of the examined aspects. The ISO 14,001 standard has a minimal impact on process rationalization. In turn, the implementation of a quality management system according to ISO 9001 does not improve the implementation of environmental issues to a small extent.

In summary, it can be said that enterprises operating in the textile industry should consider implementing standardized management systems. These systems, by supporting and complementing each other, will allow for more efficient and effective management of a sustainable supply chain. The integration of standardized management systems in the supply chain allows for the development of a comprehensive approach to process management. If the systems functioned separately, the focus would be on various aspects of management.

Author Contributions: conceptualization, D.Z.; methodology, D.Z., P.M. and R.S.; formal analysis, D.Z., P.M.; data curation, D.Z. and P.M.; writing —original draft preparation, D.Z.; writing—review and editing, D.Z., P.M. and R.S.; visualization, D.Z.; supervision, D.Z.; project administration, D.Z.; funding acquisition, D.Z. All authors have read and agreed to the published version of the manuscript.

Funding: This research was supported by grant VEGA 0663/18 Requirements non-linearity and its integration into quality management process.

Conflicts of Interest: The authors declare no conflict of interest.

\section{References}

1. Raut, R.; Gardas, B.B.; Narkhede, B. Ranking the barriers of sustainable textile and apparel supply chains: An interpretive structural modelling methodology. Benchmark. Int. J. 2019, 26, 371-394. [CrossRef]

2. Norris, L. Urban prototypes: Growing local circular cloth economies. Bus. Hist. 2019, 61, 205-224. [CrossRef] 
3. Zimon, D.; Domingues, P. Proposal of a concept for improving the sustainable management of supply chains in the textile industry. Fibres Text. East. Eur. 2018, 26, 8-12. [CrossRef]

4. Palomo-Lovinski, N.; Copeland, L.; Kim, J. Perceptions of sustainability curriculum in US fashion academia. Int. J. Fash. Des. Technol. Educ. 2019, 12, 364-373. [CrossRef]

5. Nayak, R.; Akbari, M.; Far, S.M. Recent sustainable trends in Vietnam's fashion supply chain. J. Clean. Prod. 2019, 225, 291-303. [CrossRef]

6. Nguyen, X.; Doan, T.; Hoang, V. The impact of global supply chain management on performance: Evidence from Textile and garment industry. Uncertain Supply Chain Manag. 2020, 8, 17-26. [CrossRef]

7. Moazzem, S.; Daver, F.; Crossin, E.; Wang, L. Assessing environmental impact of textile supply chain using life cycle assessment methodology. J. Text. Inst. 2018, 109, 1574-1585. [CrossRef]

8. Aakko, M.; Koskennurmi-Sivonen, R. Designing sustainable fashion: Possibilities and challenges. Res. J. Text. Appar. 2013, 17, 13-22. [CrossRef]

9. Jawaad, M.; Zafar, S. Improving sustainable development and firm performance in emerging economies by implementing green supply chain activities. Sustain. Dev. 2020, 28, 25-38. [CrossRef]

10. Kang, J.; Liu, C.; Kim, S.H. Environmentally sustainable textile and apparel consumption: The role of consumer knowledge, perceived consumer effectiveness and perceived personal relevance. Int. J. Consum. Stud. 2013, 37, 442-452. [CrossRef]

11. Oelze, N. Sustainable supply chain management implementation-enablers and barriers in the textile industry. Sustainability 2017, 9, 1435. [CrossRef]

12. Moorhouse, D.; Moorhouse, D. Sustainable design: Circular economy in fashion and textiles. Des. J. 2020, 20 (suppl. 1), S1948-S1959. [CrossRef]

13. Trejo, H.X.; Smith, H.A.; Trejo, N.K.; Lewis, T.L. Made in New York: A collaborative model to encourage slow fashion. Cloth. Text. Res. J. 2019, 37, 139-154. [CrossRef]

14. McNeill, L.S.; Snowdon, J. Slow fashion-Balancing the conscious retail model within the fashion marketplace. Australas. Mark. J. 2019, 27, 215-223. [CrossRef]

15. Sroufe, R.; Curkovic, S. An examination of ISO 9000: 2000 and supply chain quality assurance. J. Oper. Manag. 2008, 26, 503-520. [CrossRef]

16. Hashim, M.; Baig, S.A.; Amjad, F.; Nazam, M.; Akram, M.U. Impact of Supply Chain Management Practices on Organizational Performance and Moderating Role of Innovation Culture: A Case of Pakistan Textile Industry. Int. Conf. Manag. Sci. Eng. Manag. 2019, 390-401.

17. Suhardi, A.R.; Rozak, A. Supply chain management and total quality management in textile manufacturing companies. J. Adv. Res. Dyn. Control Syst. 2019, 11, 173-177.

18. Bag, S.N.; Kumar, U.C.; Pal, A.K. Status and scope of the jute industry in India in comparison to other world producers. Fibres Text. East. Eur. 2016, 24, 19-25. [CrossRef]

19. Tay, H.H.; Ariffin, M.; Sharaai, A.H. Key factors for adoption of ISO 14001 by the manufacturing industry: A review paper. Int. J. Product. Qual. Manag. 2018, 25, 90-107. [CrossRef]

20. Tuczek, F.; Castka, P.; Wakolbinger, T. A review of management theories in the context of quality, environmental and social responsibility voluntary standards. J. Clean. Prod. 2018, 176, 399-416. [CrossRef]

21. Seman, N.A.A.; Govindan, K.; Mardani, A.; Zakuan, N.; Saman, M.Z.M.; Hooker, R.E.; Ozkul, S. The mediating effect of green innovation on the relationship between green supply chain management and environmental performance. J. Clean. Prod. 2019, 229, 115-127. [CrossRef]

22. Curkovic, S.; Sroufe, R. Using ISO 14001 to promote a sustainable supply chain strategy. Bus. Strategy Environ. 2011, 20, 71-93. [CrossRef]

23. Graafland, J.J. Ecological impacts of the ISO14001 certification of small and medium sized enterprises in Europe and the mediating role of networks. J. Clean. Prod. 2018, 174, 273-282. [CrossRef]

24. Zimon, D.; Madzik, P. Impact of Implementing ISO 14001 Standard Requirements for Sustainable Supply Chain Management in the Textile Industry. Fibres Text. East. Eur. 2019, 27, 8-14. [CrossRef]

25. Castka, P. Modelling firms' interventions in ISO 9001 certification: A configurational approach. Int. J. Prod. Econ. 2018, 201, 163-172. [CrossRef]

26. Su, H.C.; Kao, T.W.D.; Linderman, K. Where in the supply chain network does ISO 9001 improve firm productivity? Eur. J. Oper. Res. 2020, 283, 530-540. [CrossRef]

27. Sroufe, R. Integrated Management_-How Sustainability Creates Value for Any Business; Emerald Press: Castle Hill, Australia, 2018. 
28. Sroufe, R. Integration and organizational change towards sustainability. J. Clean. Prod. 2017, 162, 315-329. [CrossRef]

29. Dellana, S.; Kros, J. ISO 9001 and supply chain quality in the USA. Int. J. Product. Perform. Manag. 2018, 67, 297-317. [CrossRef]

30. Zimon, D.; Madzík, P. Standardized management systems and risk management in the supply chain. Int. J. Qual. Reliab. Manag. 2020, 37, 305-327. [CrossRef]

31. Bastas, A.; Liyanage, K. Sustainable supply chain quality management: A systematic review. J. Clean. Prod. 2018, 181, 726-744. [CrossRef]

32. Shim, S.; Kim, J.; Na, Y. An exploratory study on up-cycling as the sustainable clothing life at home. Fash. Text. 2018, 5, 14. [CrossRef]

33. Flynn, B.B.; Flynn, E.J. Synergies between supply chain management and quality management: Emerging implications. Int. J. Prod. Res. 2005, 43, 3421-3436. [CrossRef]

34. Casadesús, M.; de Castro, R. How improving quality improves supply chain management: Empirical study. TQM Mag. 2005, 17, 345-357. [CrossRef]

35. Hernandez-Vivanco, A.; Domingues, P.; Sampaio, P.; Bernardo, M.; Cruz-Cázares, C. Do multiple certifications leverage firm performance? A dynamic approach. Int. J. Prod. Econ. 2019, 218, 386-399. [CrossRef]

36. Foster, S.T. Towards an understanding of supply chain quality management. J. Oper. Manag. 2008, 26, 461-467. [CrossRef]

37. Talapatra, S.; Santos, G.; Uddin, K.; Carvalho, F. Main benefits of integrated management systems through literature review. Int. J. Qual. Res. 2019, 13, 1037-1054. [CrossRef]

38. Dellana, S.; Kros, J.F.; Falasca, M.; Rowe, W.J. Risk management integration and supply chain performance in ISO 9001-certified and non-certified firms. Int. J. Product. Perform. Manag. 2020. [CrossRef]

39. Cabecinhas, M.; Domingues, P.; Sampaio, P.; Bernardo, M.; Franceschini, F.; Galetto, M.; Gianni, M.; Gotzamani, K.; Mastrogiacomo, L.; Hernandez-Vivanco, A. Integrated management systems diffusion models in South European countries. In. J. Qual. Reliab. Manag. 2018, 35, 2289-2303. [CrossRef]

40. Heras-Saizarbitoria, I.; Boiral, O. ISO 9001 and ISO 14001: Towards a research agenda on management system standards. Int. J. Manag. Rev. 2013, 15, 47-65. [CrossRef]

41. Ozusaglam, S.; Robin, S.; Wong, C.Y. Early and late adopters of ISO 14001-type standards: Revisiting the role of firm characteristics and capabilities. J. Technol. Transf. 2018, 43, 1318-1345. [CrossRef]

42. Koszewska, M. Circular economy in textiles and fashion-the role of a consumer. In Circular Economy in Textiles and Apparel; Woodhead Publishing: Cambridge, UK, 2019; pp. 183-206.

43. Perry, P.; Towers, N. Determining the antecedents for a strategy of corporate social responsibility by smalland medium-sized enterprises in the UK fashion apparel industry. J. Retail. Consum. Serv. 2009, 16, 377-385. [CrossRef]

44. Rynek Mody w Polsce, Raport KPMG . Available online: https://home.kpmg/pl/pl/home/insights/2019/11/raportkpmg-pt-rynek-mody-w-polsce-wyzwania.html (accessed on 15 May 2020).

45. Dyczewski, B.; Koszewska, M.; Rahman, O.; Kharb, D. Międzynarodowe uwarunkowania postaw nabywców odzieży wobec mody. Na przykładzie Polski, Kanady i Indii. Rocz. Kult. 2018, 9, 105-118. [CrossRef]

46. Freise, M.; Seuring, S. Social and environmental risk management in supply chains: A survey in the textile industry. Logist. Res. 2015, 8, 1-12. [CrossRef]

47. Baskaran, V.; Nachiappan, S.; Rahman, S. Indian textile suppliers' sustainability evaluation using the grey approach. Int. J. Prod. Econ. 2012, 135, 647-658. [CrossRef]

48. Fonseca, L.M.; Lima, V.M. Impact of supplier management strategies on the organizational performance of ISO 9001 certified organizations. Qual. Innov. Prosper. 2015, 19, 32-54. [CrossRef]

49. Nadae, J.D.; Carvalho, M.M.; Vieira, D.R. Exploring the influence of environmental and social standards in integrated management systems on economic performance of firms. J. Manuf. Technol. Manag. 2019, 30, 840-861. [CrossRef]

50. Fonseca, L.; Martins, C.; Fonseca, D. ISO 14001: 2015: An improved tool for sustainability. J. Ind. Eng. Manag. 2015, 8, 37-50.

51. Jia, P.; Diabat, A.; Mathiyazhagan, K. Analyzing the SSCM practices in the mining and mineral industry by ISM approach. Resour. Policy 2015, 46, 76-85. [CrossRef]

52. Matos, S.; Hall, J. Integrating sustainable development in the supply chain: The case of life cycle assessment in oil and gas and agricultural biotechnology. J. Oper. Manag. 2007, 25, 1083-1102. [CrossRef] 
53. Matos, S.; Silvestre, B.S. Managing stakeholder relations when developing sustainable business models: The case of the Brazilian energy sector. J. Clean. Prod. 2013, 45, 61-73. [CrossRef]

54. Carter, C.R.; Easton, P. Sustainable supply chain management: Evolution and future directions. Int. J. Phys. Distrib. Logist. Manag. 2011, 41, 46-62. [CrossRef]

55. Govindan, K.; Khodaverdi, R.; Jafarian, A. A fuzzy multi criteria approach for measuring sustainability performance of a supplier based on triple bottom line approach. J. Clean. Prod. 2013, 47, 345-354. [CrossRef]

56. Yeung, A.C.L. Strategic supply management, quality initiatives, and organizational performance. J. Oper. Manag. 2007, 26, 490-502. [CrossRef]

57. Dong, S.; Xu, S.X.; Zhu, K.X. Research Note-Information Technology in Supply Chains: The Value of IT-Enabled Resources Under Competition. Inf. Syst. Res. 2009, 20, 18-32. [CrossRef]

58. Chiarini, A.; Castellani, P.; Rossato, C. Factors for improving performance in ISO 9001 certified small- and medium-sized service enterprises. TQM J. 2020, 32, 21-37. [CrossRef]

59. Mijatovic, I.; Maricic, M.; Horvat, A. The Factors Affecting the Environmental Practices of Companies: The Case of Serbia. Sustainability 2019, 11, 5960. [CrossRef]

60. Santos, G.; Rebelo, M.; Lopes, N.; Alves, M.R.; Silva, R. Implementing and certifying ISO 14001 in Portugal: Motives, difficulties and benefits after ISO 9001 certification. Total Qual. Manag. Bus. Excell. 2016, 27, 1211-1223. [CrossRef]

61. Binner, H.F. Nachhaltige Qualitätsmanage-ment-Systemumsetzung durch den Organisation 4.0-Ansatz. Zwf Z. Für Wirtsch. Fabr. 2019, 114, 187-190. [CrossRef]

62. Zimon, D.; Gajewska, T.; Malindzakova, M. Implementing the requirements of ISO 9001 and improvement logistics processes in SMES which operate in the textile industry. Autex Res. J. 2018, 18, 392-397. [CrossRef]

63. Chountalas, P.T.; Magoutas, A.I.; Zografaki, E. The heterogeneous implementation of ISO 9001 in service-oriented organizations. TQM J. 2020, 32, 56-77. [CrossRef]

64. Fonseca, L.M.; Domingues, J.P. The best of both worlds? Use of Kaizen and other continuous improvement methodologies within Portuguese ISO 9001 certified organizations. TQM J. 2018, 30, 321-334. [CrossRef]

65. Domingues, P.; Sampaio, P.; Arezes, P.M. Integrated management systems assessment: A maturity model proposal. J. Clean. Prod. 2016, 124, 164-174. [CrossRef]

66. Para-González, L.; Mascaraque-Ramírez, C. The importance of official certifications in globalized companies' performance: An empirical approach to the shipbuilding industry. Corp. Soc. Responsib. Environ. Manag. 2019, 26, 408-415. [CrossRef]

67. Tarí, J.J.; Molina-Azorín, J.F.; Heras, I. Benefits of the ISO 9001 and ISO 14001 standards: A literature review. J. Ind. Eng. Manag. 2012, 5, 297-322. [CrossRef]

68. Siltori, P.F.; Simon Rampasso, I.; Martins, V.W.; Anholon, R.; Silva, D.; Souza Pinto, J. Analysis of ISO 9001 certification benefits in Brazilian companies. Total Qual. Manag. Bus. Excell. 2020. [CrossRef]

69. İlkay, M.S.; Aslan, E. The effect of the ISO 9001 quality management system on the performance of SMEs. Int. J. Qual. Reliab. Manag. 2012, 29, 753-778. [CrossRef]

70. Zimon, D.; Dellana, S. A longitudinal exploratory study of ISO 9001 certification abandonment in small- and medium-sized enterprises. Int. J. Qual. Reliab. Manag. 2020, 37, 53-67. [CrossRef]

71. Wolniak, R. The assessment of significance of benefits gained from the improvement of quality management systems in Polish organizations. Qual. Quant. 2013, 47, 515-528. [CrossRef]

72. Sansalvador, M.E.; Brotons, J.M. Valuation of the option of abandoning ISO 9001 certification: An empirical study in Spain. Total Qual. Manag. Bus. Excell. 2015, 26, 1255-1268. [CrossRef]

73. Terziovski, M.; Power, D.; Sohal, A.S. The longitudinal effects of the ISO 9000 certification process on business performance. Eur. J. Oper. L Res. 2013, 146, 580-595. [CrossRef]

74. Cogollo-Flórez, J.M.; Correa-Espinal, A.A. Analytical modeling of supply chain quality management coordination and integration: A literature review. Qual. Manag. J. 2019, 26, 72-83. [CrossRef]

75. Bastas, A.; Liyanage, K. ISO 9001 and supply chain integration principles based sustainable development: A Delphi study. Sustainability 2018, 10,1-15. [CrossRef]

(C) 2020 by the authors. Licensee MDPI, Basel, Switzerland. This article is an open access article distributed under the terms and conditions of the Creative Commons Attribution (CC BY) license (http://creativecommons.org/licenses/by/4.0/). 